\section{RACIP-2}

The 2nd International Conference on Research and Communications in Physics (the first was held nine years ago in the US) took place at the United Nations University in Tokyo on 18-22 September 1995. It was organized by the Physical Society of Japan and the Japan Society of Applied Physics in coordination with the American Physical Society, the EPS, the Asia-Pacific Association of Physical Societies, and the United Nations University. H. Schopper, the EPS President, gave a talk in the opening session entitled Perspectives Towards the 21st Century (available at http:// epswww. wpfl.ch on EurophysNet under EPS Presentations) while N. Kroó, the EPS VicePresident spoke on east-west activities and led a panel discussion on east-west cooperation. new synchrotron radiation which recently came into operation testifies to the county's commitment to the importance of basic research. North Korea is also interested in joining the ITER fusion project.

One was impressed by the extent to which physicists from the US have managed to build up activities in all of the areas which were discussed. This is partly because they have a large national physical society. Europe in contrast is split and cannot yet speak with one voice. It became clear that

\title{
PHYSICS FOR DEVELOPMENT
}

\section{Helping to Reach a Minimum Level}

\begin{abstract}
Annick Suzor-Weiner, Professor of Chemical Physics at the University of Paris VI, who chairs the EPS Interdivisional Group of Physics for Development describes the Group's work which now favours joint initiatives.
\end{abstract}

The European Physical Society has always felt that there is a strong mutual interest in scientific collaboration between the more industrialised countries of northern Europe and the less advanced ones inside as well as outside Europe. This attitude was crystallised in March 1985 by launching the Interdivisional Group of Physics for Development (IGPD) chaired by Endre Lillethun from Bergen. The IGPD's 10th anniversary is an appropriate opportunity for reviewing its scope, past achievements and future perspectives.

\section{Focusing on Education and Research}

Some 220 members of EPS and national physical societies are presently IGPD members. As for all EPS Divisions and Groups, they joined by contacting the EPS Secretariat or their national society. Other individuals may be invited to participate in specific activities. A Board of 10 , including the Chairman and the Secretary, is elected by the Group's members for no longer than six years, with at least half of the Board being renewed every three years. The Board, to which a few co-opted members may be added, has overall responsibility for the Group's activities and reports to the EPS Council. It was chaired until earlier this year by Lennart Hasselgren from Uppsala who took over from Endre Lillethun in 1992.

The IGPD's overall goal is to strengthen physics and physicsrelated research and education in developing countries, i.e., countries which have not yet reached the same level of technical and industrial development as northern Europe and North America. This obviously covers a broad range of situations each calling for a different approach.

Most colleagues in northern Europe are easily convinced of

the mutual benefits stemming from collaboration with east and central Europe and southern Europe, whose well-trained young physicists may contribute much. Links with several countries in Asia and South America undergoing rapid development are also sought. However, physicists often question the value of scientific cooperation with some countries, such as many in central Africa, where the general situation is so bad that other aspects seem much more urgent. The IGPD believes that any country needs a minimum level of scientific potential and education to avoid complete technological dependence, to relate imported technologies to local resources, and to be able to grasp any opportunity for improving living conditions. It aims to help create links between universities, institutions and individuals that enhance this indispensable potential.

Whatever the level of development, the Group focuses on collaboration between groups in developing countries from the same region, and on long-term collaborative research under the joint responsibility of physicists from both developing and more industrialised countries. To help initiate projects, the IGPD promotes the organization of meetings, preferably workshops and summer schools held in developing

A modern, large-scale solar energy plant, in southern USA.

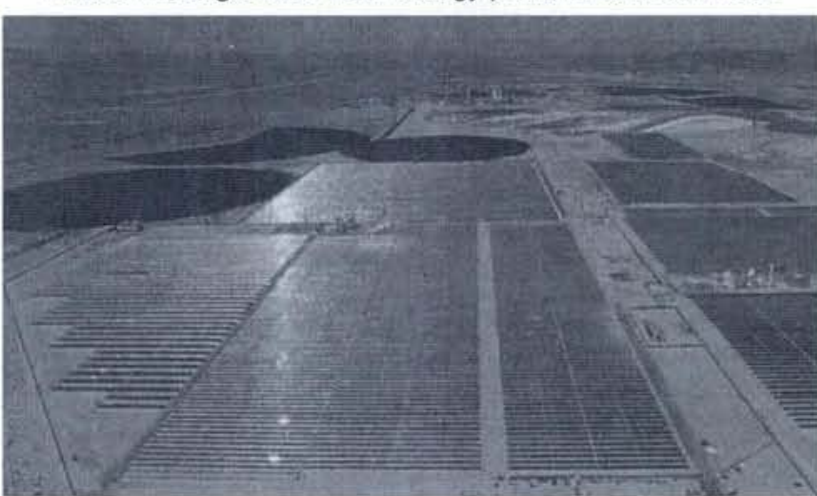

the EPS has to be strengthened if Europe wants to make a comparable contribution towards tackling the difficult issues that physics faces at the world-wide level.

The conference organizers agreed that a third event would be useful. Since the APS will be celebrating its 100 th anniversary in 1999 with a series of major events, it was decided that RACIP-3 should be in 2000 in Europe.

H. Schopper, EPS President

countries. As it has few resources for cooperation, the IGPD's possibilities are of course modest. But we can offer effective input towards developing long-term collaboration and training. Contacts with organizations supporting physics in developing countries (e.g., Third-World Academy of Sciences, International Program in the Physical Sciences, International Atomic Energy Agency, UNESCO) are essential to ensure complementarity and efficiency.

\section{A Range of Activities}

The IGPD has managed several very successful activities and some new initiatives are underway.

- Workshop on solar energy: One of the first, and most fruitful, activities of IGPD was to organize a workshop entitled Planning of Network Projects in Materials Science and Solar Energy in Nairobi, Kenya, in 1988. There were 52 participants from 18 African countries (from both English- and Frenchspeaking regions which was unusual) as well as 14 specialists from Europe. Besides the strong interest in exchanging scientific information, a concrete outcome were plans for new or enhanced cooperation projects (e.g., a collaboration between Senegal, Egypt, Thailand, Germany, and France on the study of special solar equipment in different types on southern climates, and another between Tanzania, Ethiopia, Kenya, Sudan, Uganda, Zambia, and Sweden in the field of photovoltaic cells).

- Southern European School of Physics: Southern Europe has few training schools because the institutional infrastructure that offers and promotes courses is lacking. Initiated by Henri van Regemorter (Meudon Observatory) and Siegbert Raither (UNESCO, Paris), the Southern European Schools of Physics aim at providing supplementary training for talented Ph.D. physics students and young post-doctoral physicists from Europe, through interaction with senior scientists and between young physicists from different countries. Each is hosted by a different institution whose main research field matches the topic of the school. Funding was to be provided by UNESCO, the European Commission and the Council of 


\section{Directories of Physics in Africa}

[1] A Catalogue on Research Activities in Physics and Related Fields in Eastern and Southern Africa, Eds.: L. Hasselgren and R. Kivaisi; available free of charge from IPPS Uppsala Univ., Dag Hammarskjölds vag 31 , S-752 37 Uppsala (fax: $+46-18-1834$ 95)

[2] A Catalogue on Research Activities in Physics and Related Fields in Northern and Western Africa (in preparation). A questionnaire is being sent to universities and institutions in the region. If you are collaborating with an active group, or if you want further information or to receive the questionnaire, please contact: P. Brault, IGPD Secretary, GREMI, Université d'Orléans, BP 6759, F45067 Orléans Cedex (tel.: +33-38 4171 25; fax: +33-38 4171 54; brault @ univ-orleans.fr).

Europe but this has not always been possible so some planned schools had to be cancelled. Two have been held to date (Dynamical Processes in Molecular Physics in September 1991 in Avila under G. Delgado-Barrio from Madrid; Lasers and Applications in Heraklion in May 1994 under C. Fotakis from Heraklion). The outcome of the first two schools was very positive, largely owing to the quality of the interactions between participants. The IGPD feels strongly that this activity must continue, with a new location and topic each time. Extension of the geographic area to both eastern Europe and to all countries around the Mediterranean should be encouraged. Unfortunately, financing has been too problematic to allow the schools to be held on a regular basis. The IGPD will be collaborating in the organization of the third school that is being planned for Portugal in 1997, for which there are positive signs of support from some new funding sources.

- Satellite meetings: Since its foundation the IGPD has worked hard to remind participants at the triennial EPS General Conferences of the problems physicists face in developing countries and of the need for cooperation between countries inside and outside Europe. For instance, a satellite meeting to EPS-8 (Enschede, 1990) organized by $M$. Rodot and D. Feil on Physics and Physicists for Development attracted more that 60 participants from 23 countries and resulted in a widely distributed declaration. At EPS-9 (Florence, 1993), two IGPD members ( $F$. Brouillard and C.G. Granqvist) gave talks during a session on Physics in a Changing World. In collaboration with the Action Committee for Physics and Society, we aim to organize a satellite school on Renewable Energies (mainly solar energy and related topics) after EPS-10 (Sevilla, September 1996).

- Conferences: A conference in Dakar on spectroscopic methods in physics is planned for early-1997. As usual, we intend to favour joint initiatives with other EPS bodies concerned with education and applied physics, notably the Action Committee for Physics and Society, the Interdivisional Group for Education, the new Interdivisional Group for Applied Physics and Physics and Industry, since technological development implies commitments in all these aspects.
-Directories: A catalogue on research activities in physics and related fields in north and west Africa is being prepared by the IGPD with help from the International Program in Physical Sciences, Uppsala, which published a similar catalogue for east and southern Africa in 1994 [1]. The aim is to present active research groups, with an emphasis on experimental and teaching facilities, so as to stimulate regional cooperation by avoiding duplication [2]

More generally, it is the contribution of all its members which makes the IGPD visible and efficient. We believe that the Group's main resource comprises people having considerable knowledge and experience and that direct links between institutions or individuals in countries at different stages of development are more effective than solemn declarations. We aim to seize opportunities being offered by the European Union (EU) for supporting scientific collaboration, notably the many interesting oppor- tunities for physics-related topics which are available outside the EU Training and Mobility of Researchers programme (e.g., the JOULE and THERMIE for research on energy). Improving teaching and training in physics, from the first year at university (or even secondary school) to the graduate level, are of primary importance and here we may be able to obtain substantial support from the EU via ALFA (academic formation in South America), TEMPUS and TACIS (for east and central Europe and the former Soviet Union), MEDCAMPUS (for countries around the Mediterranean), and CAMPUS (for African countries). Several bilateral programmes for cooperation between Europe and developing countries are also open to physics-related research. If we promote collaborations by circulating information on funding sources and enabling direct contacts during schools and conferences, the IGPD will continue to help bridge the scientific and technical gaps between countries at various stages of development.

\section{EMSOS}

\section{EMSPS Scheme Continues to Expand}

The Mobility Committee reviewed the European Mobility Scheme for Physics Students and other activities during a meeting in Belfast on 21-23 September 1995.

It is a little earlier to estimate exactly how many students will move this year between institutions participating in the European Mobility Scheme for Physics Students (EMSPS) scheme which is the managed by the EPS Mobility Committee. But the number will certainly be larger than the 253 for the 1994/5 academic year so the scheme continues to grow.

Many students moving between participating institutions located within European Union (EU) countries receive grants funded by the EU'S ERASMUS programme. ERASMUS has been absorbed into the new SOCRATES programme, but to give universities time to coordinate applications for mobility grants, the European Commission (EC) decided in June to delay implementing of the ERASMUS part of SOCRATES funding. The committee has prepared an application for a renewal of its ERASMUS Interuniversity Coordination Project in 1996/97 which takes into account the fact that the SOCRATES transitional measures allow neither "internal expansion" nor new participating institutions. Since Switzerland does not participate in SOCRATES there will be no ERASMUS under SOCRATES mobility grants for students moving into or out of Switzerland as from the 1996/97 academic year. However, the Swiss authorities are preparing measures to award grants to both incoming and outgoing students (details will be known later this year).

The EMSPS made applications in 1994 to the EU's TEMPUS programme for mobility grants for students moving in 1994-97 between EU countries and a total of eight east and central European (ECE) countries. Applications covering Hungary, Latvia and Poland were successful, those for the Czech Republic, Lithuania and Romania being unsuccessful because the national TEMPUS authorities did not include student mobility in science as a priority. The situation has fortunately changed somewhat since TEMPUS applications for Lithuania and Romania covering some 10 institutions in the period 1995-98 have been accepted.

Students from some 24 EMSPS participating institutions in Austria, Hungary, Poland, Slovakia, and Slovenia are also eligible for mobility grants awarded by the Central European Exchange Programme for University Studies (CEEPUS). H. Latal, the EMSPS Chairman, reported that 81 CEEPUS scholarship-months have been awarded to 23 institutions for 1995/96, a sizable increase from the 10 that were taken up in the last semester of the 1994/95 academic year when CEEPUS was launched.

The Soros Foundations have been supporting mobility grants awarded by EPS to students moving from ECE to institutions in western Europe. Unfortunately, priorities have changed and it now seems unlikely that the programme will continue beyond the 1995/6 academic year.

The EMSPS database in Manchester is a vital element of the scheme as it allows students and their coordinators to identify suitable courses. Information about courses 